\title{
Avaliação de um programa para ensinar comportamento empático para crianças em contexto clínico
}

\author{
Aline Vettorazzi; Eluana Frare \\ Fernanda Chedid de Souza \\ Fernanda Pamplona de Queiroz. \\ Gabriel Gomes de Luca \\ Luciana Moskorz \\ Olga Mitsue Kubo \\ Universidade Federal de Santa Catarina
}

\begin{abstract}
RESUMO
O comportamento empático, entendido como uma classe geral de comportamentos, tem sido considerado necessário para o bom estabelecimento de relações interpessoais. Para a apresentação desse comportamento, muitas vezes é necessária uma intervenção profissional para que ele seja aprendido. Foi objetivo do trabalho avaliar um programa para o ensino desse comportamento para crianças, em contexto clínico. Para construir o programa, o comportamento empático foi decomposto em aprendizagens intermediárias. O ensino dos comportamentos identificados foi feito de maneira gradual, por meio de atividades lúdicas planejadas para ocorrerem sob contingências de reforço positivo. Foram desenvolvidas atividades para o ensino de 09 dos 25 comportamentos intermediários identificados. Desses, sete foram aprendidos pela criança durante as sessões. Os resultados possibilitam evidenciar que, quando o ensino é programado, a aprendizagem ocorre de maneira a possibilitar ao terapeuta intervir mais precisamente sobre aqueles comportamentos que estão com mais dificuldades para serem aprendidos aumentando, dessa forma, a eficiência do atendimento. Ademais, a clara explicitação das aprendizagens intermediárias possibilitou a escolha, criação e adaptação de atividades lúdicas que melhor atendessem ao objetivo proposto para cada encontro, aumentando, dessa maneira, as possibilidades de aprendizagem dos comportamentos relevantes para a criança comportarse mais empaticamente.
\end{abstract}

Palavras-chave: programação de ensino; comportamento empático; contingências de reforço.

\begin{abstract}
Evaluation of a program to teach emphatic behavior for children in clinic context

Emphatic behavior, understood like a class of behaviors, has been considerate necessary for the good establishment of interpersonal relationships. Presenting these behaviors sometimes requires professional intervention for them to be learned. Therefore, the objective of this article was evaluating a program for teaching these behaviors for children, in a clinical context. For elaborating the program, emphatic behavior was decomposed in intermediary learning steps. Teaching the identified behaviors was made in a gradual form, by playful activities projected for occurring in a positive contingence of reinforcement. Activities were developed to teach 9 out of the 25 intermediary behaviors identified. The children learned 7 of those 9 behaviors that were teached during therapeutic sessions. The results enabled identifying that, when teaching is programmed, learning occurs in a way to make it possible for the therapist to follow more frequently and intervene more accurately in that specific behavior that presents more difficulties for being learned and, this way; amplify the efficiency of the intervention. In addition, the explicitness of intermediary learning steps makes the choice, creation and adaptation of playful activities possible, which better attends the proposed objectives for each session, keeping children motivated and increasing the possibilities of learning the relevant of behavioring more emphaticly.
\end{abstract}

Keywords: teaching program; emphatic behavior; contingences of reinforcement. 
Pessoas mais empáticas conseguem estabelecer e manter melhores relacionamentos? Se a resposta a esta pergunta for afirmativa, então, será possível aprender a ser mais empático nas relações sociais tanto informais como profissionais? Estudiosos de diferentes subáreas da Psicologia têm demonstrado que o comportamento empático, entendido como uma classe geral de comportamentos, é uma das principais habilidades sociais requeridas para o estabelecimento de relações interpessoais de maior qualidade. A aprendizagem desse comportamento não só é possível, como se faz relevante considerando as exigências de, cada vez mais, "cultivar" condições de boa qualidade principalmente nas relações profissionais. Dessa forma, dada a importância da aprendizagem dessa classe geral denominada comportamento empático, faz-se relevante aferir quanto um programa elaborado com objetivo de ensino desse comportamento foi eficiente para possibilitar que uma criança aprendesse comportamentos mais específicos envolvidos nessa classe geral.

Van Der Zee e Van Oudemhoven (2000, citado por Falcone, 2002) demonstram que o comportamento empático pode atender as demandas profissionais do mundo globalizado. Caballo (1996) concorda com a importância do comportamento empático no mundo profissional, uma vez que muitos profissionais fracassam pela inexistência de um repertório comportamental adequado às contingências do contato social nas relações de trabalho.

Burleson (1985) sugere que as pessoas empáticas despertam afeto e simpatia, são mais populares e ajudam a desenvolver habilidades de enfrentamento, bem como reduzem problemas emocionais e psicossomáticos em amigos e familiares. Comportar-se empaticamente aumenta a probabilidade de provocar efeitos mais positivos que a apresentação do comportamento assertivo. Expressar-se de maneira empática, demonstrando consideração com as necessidades da outra pessoa, antes de usar a assertividade direta, pode minimizar uma avaliação negativa da assertividade (Falcone, 2002a).

Falcone (2002a), ao discorrer sobre a evolução das habilidades sociais e do comportamento empático em particular, analisa que as primeiras definições de empatia eram feitas segundo uma perspectiva cognitiva (capacidade de se colocar no lugar de outra pessoa e de entender e predizer os seus sentimentos e pensamentos), ou segundo uma perspectiva primordialmente afetiva com alguns componentes cognitivos (o indivíduo que empatiza experimenta vicariamente uma emoção que é congruente à emoção do outro). A autora examina que na atualidade o consenso é o de que a empatia engloba tanto componentes cognitivos, afetivos como comportamentais, ainda que não haja consenso entre diferentes autores sobre a definição de empatia. Conforme Del Prette e Del Prette (2005), há, no entanto, dois modelos mais aceitos sobre o desenvolvimento da empatia: um deles proposto por Feshbach $(1978 ; 1982)$ e outro por Hoffman (1982; 2000).

O modelo baseado nas proposições de Feschbach (1978; 1982, citado por Del Prette \& Del Prette, 2005) fundamenta-se em definição estrutural da empatia com ênfase em dois componentes cognitivos e um afetivo: (1) discriminação do estado emocional do outro, (2) tomada de perspectiva e (3) responsividade emocional. De acordo com Falcone (1999, 2002a), a empatia definida como uma habilidade de comunicação compreende (1) capacidade de compreender os sentimentos e perspectivas do outro; (2) preocupação e a atenção com a outra pessoa, e (3) comunicação do próprio entendimento sobre o sentimento e a perspectiva do outro, de maneira que ele se sinta compreendido. Dessa forma, o indivíduo que é empático durante uma interação apresenta comportamentos como prestar atenção e ouvir sensivelmente, sendo capaz de compreender e experienciar a perspectiva do outro. Implica colocar-se à disposição para o outro e identificar mensagens não-verbais, compreendendo-o a partir de sua verbalização, sem julgamentos prévios. É necessária também a demonstração desse entendimento de forma apropriada por meio de verbalizações empáticas (Falcone, 1999, 2002a; Del Prette \& Del Prette, 1999).

O modelo de desenvolvimento da empatia proposto por Hoffman (2000, citado por Del Prette \& Del Prette, 2005) destaca os componentes afetivos mais do que os cognitivos e define empatia como "uma reação afetiva vicária que é mais apropriada ao outro do que a si mesmo" (Hoffman, 1982, p.120). De acordo com Hoffman (2000), seis diferentes processos ocorrem desde as primeiras semanas de vida até por volta dos quatro a seis anos de idade, e variam de acordo com a diversidade de experiências do indivíduo, ou seja, "quanto maior a diversidade desses processos na experiência do indivíduo e quanto mais precocemente ocorrerem, maior a força das reações empáticas" (Del Prette \& Del Prette, 2005, p.152). Esses processos são (1) choro reativo do recém-nascido, (2) condicionamento clássico variante, (3) evocação, (4) mímica motora, (5) associação simbólica e (6) tomada de perspectiva.

Considerando comportamento empático como uma classe geral de comportamentos, é possível, segundo Del Prette e Del Prette (2005), identificar algumas 
subclasses de comportamentos fundamentais para o seu aprimoramento e desenvolvimento, como: observar; prestar atenção; ouvir o outro; demonstrar interesse e preocupação pelo outro; reconhecer/inferir sentimentos do interlocutor; compreender a situação; demonstrar respeito às diferenças; expressar compreensão pelo sentimento ou experiência do outro; etc. Em uma perspectiva da Análise do Comportamento as "habilidades de discriminar e expressar emoções têm sido associadas à competência social, principalmente pelo fato de que são pré-requisitos para outras habilidades mais complexas, como a empatia, da qual podem ser consideradas componentes encobertos" (Garcia-Serpa, Meyer \& Del Prette, 2003, p. 23).

A capacidade de comportar-se empaticamente pode ser demonstrada nos estudos sobre desenvolvimento e aprendizagem social. Os estudos sobre desenvolvimento possibilitam revelar que os seres humanos já nascem predispostos a desenvolver empatia para assegurar sobrevivência. Estudos sobre aprendizagem social sugerem que o comportamento social possui um forte componente aprendido. Bellack e Morrison (1982, citado por Caballo, 1996) indicam que essas teorias explicam a precoce aquisição dos comportamentos socialmente habilidosos por meio da observação e imitação dos comportamentos adultos pelas crianças. Dessa forma, muitas dessas pesquisas, desde o marco de Baumrind (1966) sobre tipos de controle parental, enfatizam a importância das relações parentais (tipo de relação estabelecida entre a criança e seus pais) na aprendizagem de comportamentos sociais, uma vez que são os pais, em geral, o primeiro núcleo social da criança (Löhr, 2003) e os primeiros modeladores dos comportamentos de seus filhos.

Segundo Cecconelo, Antoni e Koller (2003) as interações entre pais e filhos são permeadas por duas dimensões essenciais - as práticas educativas e os estilos parentais. Crianças que tiveram como prática educativa primordial à disciplina indutiva, caracterizada por uma modificação voluntária no comportamento por meio da identificação das consequiências decorrentes de seus comportamentos, e foram influenciadas por estilos parentais do tipo autoritativo resultante da combinação entre exigência e responsividade em altos níveis, obtiveram uma aprendizagem mais efetiva de comportamentos característicos das habilidades sociais, como assertividade, empatia, auto-estima e autoconfiança (Cecconello, Antoni \& Koller, 2003; Eagle, 2004; Lubi, 2002) e um maior grau de otimismo (Weber, Prado, Viezzer \& cols, 2004).

Estudos demonstram que um repertório deficitário em empatia pode estar associado a vários transtornos psicológicos, entre os quais a esquizofrenia, transtornos emocionais e de aprendizagem na infância e adolescência e os transtornos invasivos do desenvolvimento (Henderson, 1998; Linnell, Stechmann \& Watson, 1975; Reeve, 2001; Webster-Stratton \& Reid, 2003).

Em síntese, ao considerar que a aprendizagem do comportamento empático é fundamental para relações interpessoais de qualidade, torna-se necessária a criação de programas de ensino desse comportamento em crianças e adultos. Portanto, programas de ensino de comportamentos socialmente habilidosos, como a empatia, podem contribuir na generalização dos comportamentos aprendidos para outros contextos relacionais do indivíduo, melhorando qualitativamente os relacionamentos. O conhecimento produzido pelos analistas do comportamento, principalmente a partir da década de 60, no Brasil, possibilitou derivar procedimentos apropriados para a elaboração de programas para o ensino desse tipo de comportamento.

\section{Programação de ensino e aprendizagem do comportamento empático}

Elaborar programas de ensino é um processo que exige a apresentação de duas classes gerais de comportamentos. É necessário que o programador seja capaz de caracterizar com precisão os comportamentos que deverão ser aprendidos, e conhecer os procedimentos apropriados para programar o ensino. Para a primeira dessas etapas, é essencial a apresentação de uma série de comportamentos (por parte do programador) para que o programa de ensino desenvolvido seja realmente eficaz e eficiente. Botomé (1980, 1996), Matos (2001) e Nale (1998) afirmam que a primeira decisão importante de quem quer ensinar alguma coisa é definir exatamente o comportamento que precisa ser ensinado. Para o estabelecimento de objetivos de ensino, é necessário que o comportamento a ser ensinado sempre se refira a algo além do que geralmente se ensina, buscando comportamentos úteis e relevantes para o sujeito e para a sociedade em que ele vive.

Nessa concepção, o ponto de partida para um programa de ensino são as situações na qual o aprendiz necessitará lidar na sua vida em comunidade. O programador de ensino deve decidir quais deverão ser os resultados das ações dos aprendizes quando estes forem lidar com a realidade em que vivem. Uma outra etapa, extremamente importante, é a decisão acerca de quais comportamentos (sempre, portanto, um agir perante a sociedade) devem ser ensinados ao aprendiz para que estes resultados sejam alcançados. 
Como uma segunda etapa em um processo de programação de ensino faz-se necessária a decomposição do comportamento-objetivo em comportamentos mais simples. Segundo Botomé (1996), decompor o objetivo de ensino em comportamentos mais simples (aprendizagens-intermediárias) evidencia quais aprendizagens o aprendiz necessita desenvolver para apresentar o comportamento-objetivo. Dessa forma, é preciso verificar em qual nível de aprendizagem se encontra o sujeito, uma vez que somente observando tais aprendizagens é possível decidir sobre até qual nível de complexidade é necessário decompor o comportamento-objetivo. A decomposição termina quando o nível de complexidade das aprendizagens intermediárias é condizente com as aprendizagens que o aprendiz já apresenta.

As formas de conseqüenciação em um programa de ensino são um dos aspectos mais importantes para que a aprendizagem seja estabelecida de uma maneira eficaz e eficiente. O programador de ensino necessita elaborar alternativas inovadoras para a criação de contingências que possibilitem a emissão da resposta que se deseja ensinar, assim como conseqüências gratificantes para o sujeito envolvido no programa. Matos (2001) disserta sobre a importância do estabelecimento de contingências naturais para uma aprendizagem efetiva. A autora afirma que conseqüências naturais são mais eficientes, uma vez que apresentam efeitos mais fortes e duradouros na apresentação do comportamento, além de permitirem a generalização do comportamento em uma variedade maior de situações.

Outras características importantes para a elaboração de um programa de ensino são: o reforço imediato à emissão da resposta que se deseja ensinar, o reforço somente às respostas efetivamente emitidas pelo aprendiz, o uso de consequiências naturais (e, se for o caso, a passagem gradual de consequiências artificiais para as conseqüências naturais), o uso da progressão gradual para o estabelecimento do comportamentoobjetivo, a escolha cuidadosa de situações antecedentes de aprendizagem, a programação e a monitoração de respostas de observação e de imitação emitidas pelo aprendiz, o uso de procedimentos que minimizem a ocorrência de erros e a elaboração do programa a partir de algumas características do aprendiz, tais como o que ele gosta de realizar, o modo como ele o realiza, o que ele já sabe sobre um determinado assunto, entre outros (Matos, 2001; Sidman, 1985). Algumas dessas características também foram descritas sob a forma de princípios, em um texto programado acerca da programação de ensino, desenvolvido por "Teaching Machines Incorporated" (1961). Essas características são: (1) o Princípio dos Pequenos Pas- sos, (2) o Princípio da Resposta Ativa, (3) o Princípio da Verificação Imediata, (4) o Princípio do Ritmo Individual e, finalmente, (5) o Princípio do Teste da Prova.

Programação de ensino é um processo de ensinoaprendizagem que minimiza a ocorrência de erros pelos aprendizes, uma vez que errar é geralmente aversivo ao aprendiz. Eliminar ou ao menos diminuir a possibilidade de erros cometidos pelo aprendiz é uma maneira eficiente de mantê-lo mais motivado a aprender eficientemente os comportamentos-objetivo. Sidman (1985) critica a suposição de que os aprendizes aprendem com os seus erros, no conhecido processo de ensaio-e-erro. $\mathrm{O}$ autor afirma que os programadores de ensino (professores e educadores em geral) devem criar e aprimorar programas até o ponto em que os aprendizes não cometam nenhum erro. $\mathrm{O}$ erro dos aprendizes em um programa de ensino só mostra, segundo o autor, que há algo de errado com o próprio programa e não com os aprendizes, como geralmente afirmam os professores.

As primeiras tentativas de treinamento em habilidades sociais remontam à década de 60 , quando foram desenvolvidas técnicas que objetivaram aumentar a expressividade dos indivíduos. Autores como Lazarus e Wolpe (1966) e Salter (1949) todos citados por Caballo, (1996) se destacaram na implementação de tais técnicas em contextos clínico numa perspectiva comportamental, além de realizarem pesquisas sistemáticas, as quais geraram programas de treinamento para aliviar déficits de comportamentos assertivos.

Estudos demonstram resultados eficazes quando programas de treinamento da empatia são utilizados para os mais variados fins. Fine e Therrien (1977) e Kirk e Thomas (1982) desenvolveram, respectivamente, programas de treinamento para aumentar as respostas empáticas de enfermeiros psiquiátricos e de estudantes de Medicina no tratamento de seus pacientes. Falcone (1999) avaliou um programa de treinamento do comportamento empático em estudantes universitários, revelando mudanças significativas entre os sujeitos experimentais em relação aos sujeitos controle. Esse programa focalizou o ensino de capacidades como "(1) identificar sinais emocionais não-verbais no comportamento dos outros; (2) ouvir e compreender a perspectiva e os sentimentos da pessoa-alvo, sem julgar; (3) declarar entendimento da perspectiva e dos sentimentos da pessoa-alvo; (4) demonstrar a compreensão e aceitação através de comunicação nãoverbal" (p. 27). Os sujeitos do grupo experimental apresentaram desempenhos superiores aos do grupo controle ao comunicarem-se verbalmente e em quatro dos 12 comportamentos não-verbais. 
Rogge, Cobb, Johnson e cols. (2002) utilizaram programas de treinamento para fortalecer a relação entre casais, favorecendo a satisfação do relacionamento, por meio da emissão de comportamento empático. Haugen (1999) sugere ainda que programas de treinamento de empatia diminuem a probabilidade de comportamentos de agressão sexual por meio da diminuição do uso de comportamentos de auto-referência e de regras e auto-regras que predispõem ao estupro e ao abuso sexual infantil. Feshbach (1983) e Feshbach e Feshbach (1982) aplicaram programas de treinamento de empatia em crianças em idade escolar, verificando diminuição de comportamentos agressivos e aumento de comportamentos pró-sociais.

A aquisição de um novo repertório no treinamento em habilidades sociais é baseada, para Caballo (2003), na melhora progressiva de diferentes componentes moleculares que constituem cada comportamento alvo. O autor indica ainda a concretização e a operatividade como qualidades essenciais para o desenvolvimento do treinamento, sendo, portanto, necessário decompor o comportamento alvo em elementos mais simples que possam ser avaliados em sua freqüência e adequação. O olhar, a expressão facial, os gestos, a postura, a orientação corporal, a distância do contato físico, o volume da voz, a entonação, fluência, tempo de fala e sua natureza são considerados como importantes elementos moleculares no âmbito das habilidades sociais.

Alguns dos comportamentos importantes envolvidos na aprendizagem das habilidades sociais, segundo Caballo (2003) e Del Prette (1999), são saber como utilizar a quantidade e o tipo de olhar em cada interação, bem como outras condutas verbais ou não verbais, que denotam o grau de interesse de envolvimento com outras pessoas. A expressão facial mostra o estado emocional de um indivíduo proporcionando uma retroalimentação contínua durante uma interação. Os gestos constituem "um segundo canal, muito útil, por exemplo, para a sincronização e retroalimentação" (Caballo, 2003, p. 42). A postura, o contato físico e a orientação corporal são utilizados para estabelecer a proximidade e distância psicológicas. Os componentes paralingüísticos, como o volume da voz, a entonação, fluência e o tempo de fala podem afetar o significado do que se diz e de como se recebe a mensagem. As especificidades das respostas e a explicitação das funções dos comportamentos caracterizados como habilidades sociais, são o conhecimento necessário para a elaboração de um programa de ensino.

Em suma, a descoberta sistemática dos benefícios de aprender comportamentos empáticos e de habilidades sociais para a melhoria da qualidade das relações das pessoas com seu ambiente de maneira geral, tem contribuído substancialmente para o investimento na descoberta e proposição de formas de ensino dessa classe de comportamentos sociais. Estudiosos como Caballo (1996), Del Prette e Del Prette (1999; 2002; 2005), Falcone $(1999,2002)$, entre outros, tem investido na produção de conhecimento acerca desses fenômenos e tem conseguido demonstrar quanto a aprendizagem de habilidades sociais interferem na qualidade das relações das pessoas. Dessa forma, a avaliação de um programa para o ensino do comportamento empático parece ser uma importante contribuição nessa direção.

\section{MÉTODO}

\section{Sujeito}

Menino, de sete anos de idade, cursando a segunda série do ensino fundamental em uma escola da rede pública, numa cidade de médio porte do estado de Santa Catarina.

\section{Caracterização do problema a partir da queixa apresentada}

A queixa apresentada pela mãe que procurou $o$ serviço de atendimento psicológico, vinculado a um curso de graduação em Psicologia no Estado de Santa Catarina, foi de que a criança apresentava hiperatividade, inquietude motora e comportamentos autoagressivos, como se morder.

Por meio de observação direta em contexto escolar, na casa do sujeito e durante as sessões terapêuticas, foi verificado que o sujeito não apresentava comportamentos que justificasse queixa de hiperatividade apresentada pela mãe. Foi verificado que o sujeito apresentava controle motor fino apropriado, raciocínio lógico bem desenvolvido e, principalmente, concentração na realização de atividades (prestar atenção e contar histórias obedecendo à ordem cronológica, por exemplo). Entretanto, outros déficits comportamentais relacionados às habilidades sociais foram identificados, os quais diminuíam a qualidade das interações sociais do sujeito. Entre esses déficits estavam: dificuldade em demonstrar afeto, falta de contato visual, dificuldade em relatar sentimentos em relação a sua família, inquietude motora (agitar-se, mexer-se constantemente) e insegurança na realização das atividades propostas pelos atendentes, pela professora e pela sua mãe.

A identificação do problema relacionado à queixa apresentada indicou como necessária à criança a 
aprendizagem de comportamentos que pudessem propiciar uma melhoria nas qualidades das relações sociais do sujeito. Dessa forma, foi caracterizado como necessário a aprendizagem de habilidades sociais e, em especial, do comportamento empático. A escolha pelo ensino do comportamento empático foi realizada pela consideração de que, aprendido a ser mais empático, a criança diminuiria as constantes brigas com o irmão mais novo, melhoraria o relacionamento com os pais (birra, teimosia, desobediência) e suas brigas com colegas de classe, nas quais demonstrava passividade e, às vezes, crises de choro. Para Falcone (2002a) o comportamento empático "desempenha um papel na qualidade das relações interpessoais, reduzindo conflitos e aumentando vínculos" (p. 51).

\section{Descrição da situação e do ambiente}

Sala infantil da instituição na qual o atendimento foi realizado. Essa sala continha uma mesa com três cadeiras; almofadas; duas mesas pequenas com quatro cadeiras para crianças; pia com espelho; quadro-negro pequeno; dois armários com brinquedos variados (quebra-cabeças, bonecos, fantoches, jogos de memória, ludo, lego, carrinhos, lápis de cor, revistas...); um arquivo, além do espelho para observação. Este espelho pertence à sala de observação, localizada ao lado da sala de atendimento e acoplada com aparelho de som e interfone para possível comunicação dos observadores com o atendente da sessão na sala infantil. O sujeito estava ciente da presença de observadores nessa sala. Ademais, a sala de atendimento era bem iluminada e arejada, com duas janelas e um ventilador de teto. Alguns atendimentos foram realizados em salas de atendimento grupal, na mesma instituição, quando os objetivos das sessões exigiam um local com maior disponibilidade de espaço. As salas de atendimento grupal continham almofadas e um quadro-negro.

\section{Descrição dos materiais utilizados}

Para a realização das sessões foram utilizados:

1) Materiais lúdicos - jogo da memória e jogos construídos para o objetivo da sessão, como: folha contendo desenhos de variadas expressões faciais com as respectivas denominações (Brittes, 2003), jogo com duas pilhas de papéis, uma contendo o nome dos participantes e outra com as atividades a serem realizadas ("imitar galinha", "dar um longo abraço", "perceber o diferente" e "brincar de roda") e o cartaz-agenda onde eram listadas as atividades praticadas pelo sujeito nos diferentes dias da semana.

2) Papel, caneta, lápis, canetas hidrocor, cartolina.

\section{Procedimento}

\section{1) Elaboração do programa para ensino do com- portamento empático}

O comportamento empático foi o comportamentoobjetivo a ser ensinado durante as intervenções terapêuticas. Todavia, como este se configura num comportamento complexo, precisou ser decomposto em comportamentos mais simples que se constituíram em aprendizagens intermediárias. Esses comportamentos intermediários foram identificados por meio de respostas à pergunta "O que o aprendiz precisa estar apto a fazer para conseguir realizar este comportamento?" (Botomé, 1996, p.2).

Dessa forma, foi construído um mapa de ensino em que, à esquerda, localiza-se o comportamento mais complexo (comportamento empático), e à direita, comportamentos gradualmente mais simples. Os comportamentos foram decompostos até um nível em que, "provavelmente, o aprendiz já seja capaz de realizar tais comportamentos antes de iniciar o programa de ensino que você pretende desenvolver" (Botomé, 1996, p. 4). A programação de ensino realizada dessa maneira possibilitou, portanto, uma melhor visualização do que deveria ser ensinado, em qual seqüência e em que grau de aprendizagem encontrava-se o sujeito.

$\mathrm{O}$ ensino dos comportamentos intermediários foi iniciado pelos mais simples até os mais complexos e as atividades escolhidas foram, na sua maioria, jogos e brincadeiras planejadas para ocorrerem sob contingências de reforço positivo. Algumas dessas atividades envolveram classes de respostas mais próximas possíveis daquelas que provavelmente a criança encontraria em situações de seu dia a dia, visando aumentar a probabilidade de generalização para outros contextos.

\section{2) Aplicação do programa}

Foram realizadas 10 sessões semanais de atendimento à criança, com duração de uma hora cada, durante seis meses. As sessões iniciavam com um relato da criança sobre os acontecimentos da semana anterior à sessão. Finalizado o relato, iniciava-se o desenvolvimento das atividades programadas, visando a aprendizagem do comportamento que constituía o objetivo da sessão. A escolha do comportamento específico a ser ensinado em cada sessão não excluía a aprendizagem de outros comportamentos, assim como o reforçamento das aprendizagens anteriores.

As sessões eram conduzidas de acordo com os princípios do ensino programado. O sujeito era sempre convidado a participar das atividades propostas de 
forma ativa (Princípio da Resposta Ativa). O ensino dos comportamentos era realizado de forma gradual (Princípio dos Pequenos Passos), respeitando as condições individuais de aprendizagem do sujeito (Princípio do Ritmo Individual). A cada nova aprendizagem o sujeito era conseqüenciado positivamente de forma imediata (Princípio da Verificação Imediata), aumentando assim a probabilidade de ocorrência do novo repertório comportamental.

Terminadas as atividades propostas, as sessões eram finalizadas com um diálogo em que era retomado o que foi feito durante a sessão e estabelecidas tarefas para as próximas.

\section{RESULTADOS}

O processo de programar o ensino envolve necessariamente duas etapas. A primeira diz respeito à elaboração do programa de ensino envolvendo: a) a descoberta de comportamentos pré-requisitos (intermediários) a partir da decomposição da classe mais geral (comportar-se empaticamente); b) o planejamento das atividades, como condição de ensino para cada comportamento-objetivo intermediário e c) o tipo de consequiência para o ensino de cada comportamentoobjetivo. A segunda etapa refere-se à aplicação do programa propriamente dito, na qual a aprendizagem dos comportamentos do programa é verificada por meio do desempenho do sujeito e feitos reajustes no programa de acordo com a avaliação e acompanhamento desses desempenhos. Assim, o relato dos resultados está organizado em dois conjuntos pertinentes a cada uma das duas etapas componentes do processo de programar ensino.

\section{1) Elaboração do programa para ensino do com- portamento empático}

Foram identificados 25 comportamentos como resultado da elaboração do programa de ensino do comportamento empático. Na Figura 1 são apresentados esses comportamentos organizados em ordem decrescente de complexidade: à esquerda estão os comportamentos mais complexos e à direita, os mais simples.

Dos 25 comportamentos identificados como aprendizagens intermediárias do comportamento empático, nove foram objeto de ensino. Para o ensino de cada um dos comportamentos intermediários identificados, foram elaboradas atividades que possibilitaram um aumento da probabilidade de emissão da resposta desejada. Todo o ambiente terapêutico era arranjado de acordo com a atividade planejada.
Para o ensino do comportamento-objetivo "Olhar para o outro" foram planejadas duas atividadesbrincadeira: $1^{\mathrm{a}}$. "Quem pisca primeiro" - o sujeito e um dos atendentes sentam-se um em frente ao outro, mantêm contato visual e quem piscar por último ganhará a brincadeira; $2^{\mathrm{a}}$. "Modificação de algo no rosto" - os atendentes produzirão alguma mudança nos seus rostos enquanto o sujeito permanece de olhos fechados. Após será solicitado ao sujeito que observe o rosto dos atendentes e descubra quais alterações foram realizadas em seus rostos.

A terceira atividade foi "Estátua", escolhida para ensinar o comportamento de 'Esperar'. Nela os atendentes e o sujeito ficam parados em uma única posição e ganhará a brincadeira quem ficar parado por mais tempo. "Desvendar palavras sussurradas" foi a atividade planejada para ensinar os comportamentos de 'Olhar para o outro' e 'Ouvir'. A atividade consiste em descobrir a palavra que os atendentes "falam" por meio de movimentos labiais, praticamente sem som.

O comportamento-objetivo da atividade "Nomeação de expressões faciais" foi "Identificar modos de expressão verbal'. Nessa atividade é solicitado ao sujeito que nomeie as expressões sobre sentimentos ou emoções apresentadas em uma folha com desenhos de variadas expressões faciais (Brittes, 2003). Para ensino do comportamento-objetivo 'Identificar modos de expressão não-verbal em si e no outro' foi escolhida a atividade "Imitação das expressões faciais". Nesta utiliza-se o mesmo instrumento da brincadeira anterior. Os atendentes imitam uma das expressões faciais contidas no instrumento, solicita ao sujeito que a identifique e, após, que a imite.

O "Jogo da memória" foi a outra atividade planejada para o ensino do comportamento 'Esperar'. Para a realização dessa atividade os atendentes e o sujeito deverão utilizar cartões de papel padronizados contendo figuras de animais, vencendo a brincadeira quem conseguir emparelhar o maior número de cartões correspondentes. Os comportamentos-objetivo para a atividade "Telefone sem fio" foram 'Ouvir' e 'Esperar'. Participam dessa atividade tanto o sujeito como os atendentes, sendo que um deles inicia a brincadeira sussurrando uma palavra no ouvido da pessoa ao seu lado até a última pessoa da seqüência, a qual dirá aos demais participantes qual a expressão ouvida por ela.

A "Brincadeira de duas pilhas de papéis" foi a atividade planejada para o ensino do comportamento 'Tocar'. Essa atividade consiste em duas pilhas de papéis, uma contendo o nome dos participantes e outra com as atividades a serem realizadas. É sorteado 


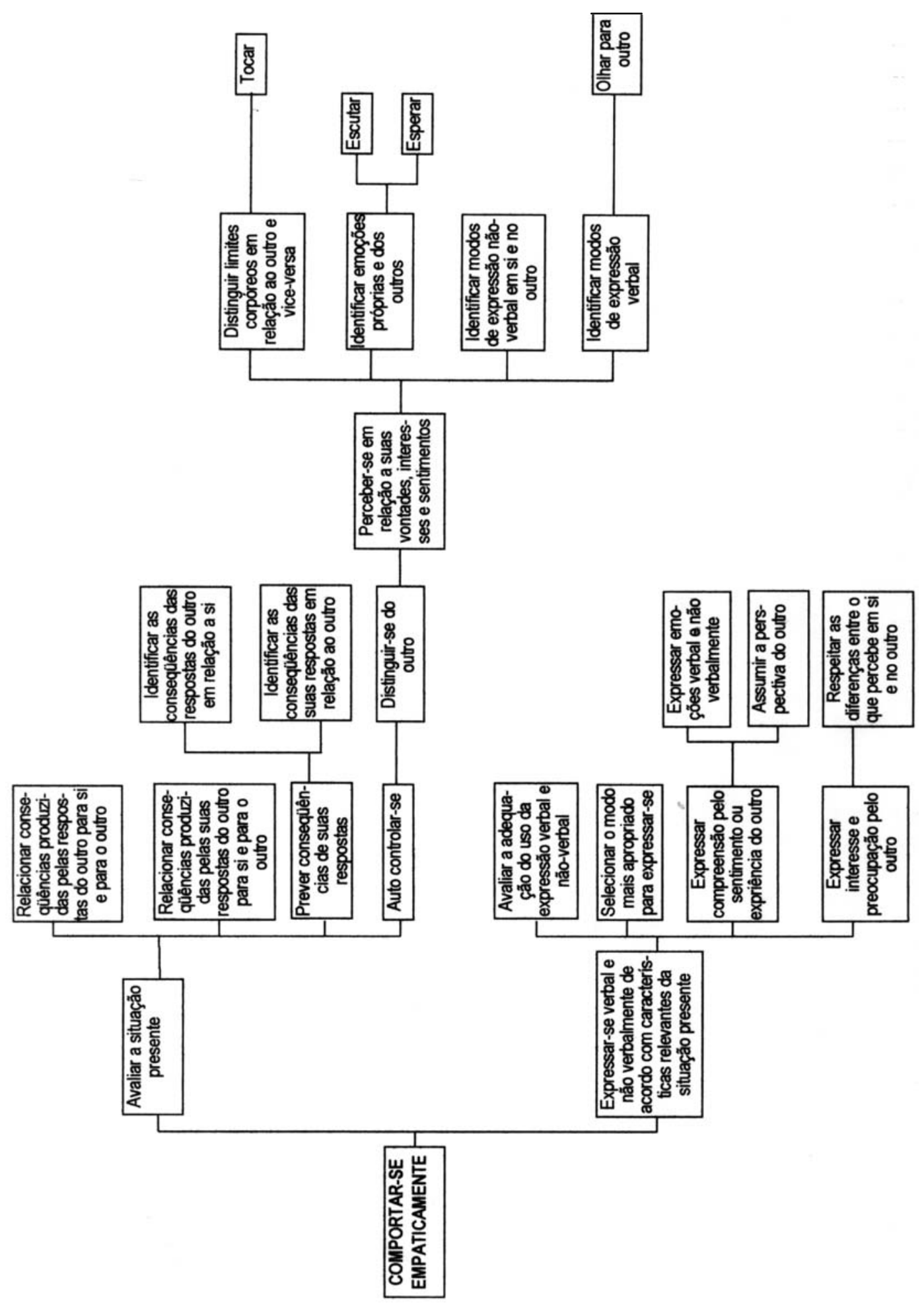

Figura 1. Comportamentos intermediários decompostos a partir da classe geral "comportar-se empaticamente", organizados em níveis de complexidade (colunas) decrescente da esquerda para a direita, a partir de Del Prette e Del Prette (1999; 2005) e Falcone (1999, 2002a). 
um papel de cada uma das pilhas e o sujeito sorteado deverá realizar a atividade descrita no papel: imitar galinha, dar um longo abraço, perceber o diferente ou brincar de roda. $\mathrm{O}$ procedimento de sorteio foi planejado de maneira que atividades que requeriam tocar fisicamente e ser tocada por outra pessoa fossem "sorteadas" para o sujeito.

A décima atividade foi a "Elaboração do cartazagenda" desenvolvida para ensinar os comportamentos 'Perceber-se em relação a suas vontades, interesses e sentimentos', 'Prever as conseqüências de suas respostas' e 'Autocontrolar-se'. Nessa atividade os atendentes, juntamente com o sujeito, listam e distribuem atividades praticadas por ele nos diferentes dias da semana, excluindo sábado e domingo. É solicitado ao sujeito que anote no próprio cartaz-agenda, em casa, as atividades que efetivamente foram realizadas dentre aquelas que estavam listadas. A outra atividade utilizada para o ensino dos três comportamentos-objetivo foi a "Verificação das atividades do cartaz-agenda". Esta consiste na verificação, pelos atendentes, de quantas atividades listadas no cartaz-agenda foram realizadas pelo sujeito durante a semana ime- diatamente anterior à sessão. Era esperado que o sujeito realizasse aproximadamente $70 \%$ das atividades listadas no cartaz-agenda.

As conseqüências planejadas para a emissão das respostas esperadas nas diferentes atividades de ensino foram, em sua maioria, imediatas e constituíram-se em reforço social caracterizado por aplausos, sorrisos e expressões verbais como "muito bem", além do reforço natural referente à obtenção de vitória nas brincadeiras. Quando o sujeito não apresentasse as respostas apropriadas para cada atividade planejada, optou-se por conseqüenciá-lo com silêncio e um pedido de nova tentativa.

\section{2) Aplicação do programa de ensino do compor- tamento empático}

Na Tabela 1 e 2 estão apresentados os comportamentos ensinados, as atividades planejadas para o ensino de cada comportamento, o desempenho do sujeito nas atividades e as consequiências apresentadas para o seu desempenho em cada uma das sessões realizadas.

Tabela 1. Desempenho do sujeito e conseqüências apresentados para o seu desempenho nas atividades realizadas para a aprendizagem dos comportamentos-objetivo intermediários identificados a partir da decomposição do comportamento empático, nas três primeiras sessões

\begin{tabular}{|c|c|c|c|c|}
\hline $\begin{array}{l}\mathrm{N}^{\circ} \text { da } \\
\text { sessão }\end{array}$ & $\begin{array}{c}\text { Comportamento } \\
\text { objetivo }\end{array}$ & $\begin{array}{c}\text { Atividade } \\
\text { desenvolvida }\end{array}$ & Desempenho do sujeito & $\begin{array}{l}\text { Conseqüência para o } \\
\text { desempenho do sujeito }\end{array}$ \\
\hline 1 & 1; 2. Olhar & $\begin{array}{l}\text { 1. Quem pisca } \\
\text { primeiro } \\
\text { 2. Modificação de } \\
\text { algo no rosto }\end{array}$ & $\begin{array}{l}\text { 1. O sujeito conseguiu manter contato } \\
\text { visual com os atendentes, vencendo-os } \\
\text { em } 6 \text { das } 8 \text { tentativas da brincadeira } \\
\text { 2. Na primeira tentativa, encontra dificul- } \\
\text { dade em perceber os detalhes modifica- } \\
\text { dos no rosto dos atendentes. Na segunda } \\
\text { tentativa, percebe os detalhes modificados }\end{array}$ & $\begin{array}{l}\text { 1, 2. Reforço social no caso de } \\
\text { acerto e silêncio e pedido de uma } \\
\text { nova tentativa no caso de erro }\end{array}$ \\
\hline 2 & $\begin{array}{l}\text { 3. Esperar } \\
\text { 4. Ouvir }\end{array}$ & $\begin{array}{l}\text { 3. Estátua } \\
\text { 4. Desvendar pala- } \\
\text { vras sussurradas }\end{array}$ & $\begin{array}{l}\text { 3. Ganhou as } 3 \text { tentativas realizadas } \\
\text { 4. Acertou } 6 \text { das } 12 \text { palavras sussurradas } \\
\text { pelos atendentes, sendo que para cada } \\
\text { acerto, foi necessário repetir a palavra em } \\
\text { média duas vezes }\end{array}$ & $\begin{array}{l}\text { 3. Reforço social } \\
\text { 4. Reforço social no caso de } \\
\text { acerto e silêncio e pedido de uma } \\
\text { nova tentativa no caso de erro }\end{array}$ \\
\hline 3 & $\begin{array}{l}\text { 6. Identificar modos de } \\
\text { expressão não-verbal } \\
\text { em si e no outro } \\
\text { 7. Esperar }\end{array}$ & $\begin{array}{l}\text { 6. Imitação de } \\
\text { expressões faciais } \\
\text { 7. Jogo de memó- } \\
\text { ria }\end{array}$ & $\begin{array}{l}\text { 5. Na primeira tentativa, descreve a ex- } \\
\text { pressão facial, mas não lhe atribui signifi- } \\
\text { cado. Da segunda a Quarta tentativa, } \\
\text { nomeia com facilidade as expressões } \\
\text { faciais. Volta a descrever a figura sem } \\
\text { atribuir-lhe significado na quinta tentativa } \\
\text { 6. O sujeito imita corretamente as expres- } \\
\text { sões nas cinco tentativas, porém pede que } \\
\text { os atendentes também imitem a expres- } \\
\text { são } \\
\text { 7. Entendeu as regras ensinadas anteri- } \\
\text { ormente ao início do jogo, demonstrando } \\
\text { paciência em esperar sua vez para jogar } \\
\text { em todas as rodadas }\end{array}$ & $\begin{array}{l}\text { 7. Conseqüência natural (na sua } \\
\text { vez de jogar, os outros jogadores } \\
\text { esperavam) }\end{array}$ \\
\hline
\end{tabular}


Tabela 2. Desempenho do sujeito e conseqüências apresentados para o seu desempenho nas atividades realizadas para a aprendizagem dos comportamentos-objetivo intermediários identificados a partir da decomposição do comportamento empático, nas sessões 4 a 10

\begin{tabular}{|c|c|c|c|c|}
\hline $\begin{array}{l}N^{\circ} \text { da } \\
\text { sessão }\end{array}$ & $\begin{array}{c}\text { Comportamento } \\
\text { objetivo }\end{array}$ & $\begin{array}{c}\text { Atividade } \\
\text { desenvolvida }\end{array}$ & Desempenho do sujeito & $\begin{array}{c}\text { Conseqüência para o } \\
\text { desempenho do sujeito }\end{array}$ \\
\hline 4 & 8. Ouvir e esperar & 8. Telefone sem fio & $\begin{array}{l}\text { 8. O sujeito acerta todas as palavras } \\
\text { que lhe se dão ditas, esperando sua vez } \\
\text { para ouvir e para falar }\end{array}$ & 8. Reforço social \\
\hline 5 & 9. Tocar & $\begin{array}{l}\text { 9. Brincadeira de } \\
\text { duas pilhas de pa- } \\
\text { péis }\end{array}$ & $\begin{array}{l}\text { 9. Na primeira tentativa de abraçar, } \\
\text { demonstrou uma resistência ao contato, } \\
\text { abraçando fortemente e largando logo } \\
\text { em seguida. Em todas as outras solici- } \\
\text { tações para abraçar, deu abraços cari- } \\
\text { nhosos e demorados }\end{array}$ & $\begin{array}{l}\text { 9. Reforço social no caso de } \\
\text { acerto e silêncio e pedido de } \\
\text { uma nova tentativa no caso de } \\
\text { erro }\end{array}$ \\
\hline 6,7 & $\begin{array}{l}\text { 10. • Perceber-se } \\
\text { em relação as suas } \\
\text { vontades, interesses } \\
\text { e sentimentos; } \\
\text { - Prever as conse- } \\
\text { qüências de suas } \\
\text { respostas; e } \\
\text { - Autocontrolar-se }\end{array}$ & $\begin{array}{l}\text { 10. Elaboração do } \\
\text { cartaz-agenda }\end{array}$ & $\begin{array}{l}\text { 10. Nas duas sessões, o sujeito demo- } \\
\text { rou para descrever as atividades e seus } \\
\text { respectivos horários. Na segunda ses- } \\
\text { são, após informado do possível pre- } \\
\text { sente que receberia com a realização } \\
\text { das tarefas, o sujeito engajou-se na } \\
\text { listagem das atividades e o cartaz- } \\
\text { agenda foi concluído }\end{array}$ & $\begin{array}{l}\text { 10. Conversa sobre os motivos } \\
\text { pelos quais não trouxe o cartaz } \\
\text { e explicação das contingências } \\
\text { de reforçamento para o cumpri- } \\
\text { mento da atividade }\end{array}$ \\
\hline $8,9,10$ & $\begin{array}{l}\text { 11. • Perceber-se } \\
\text { em relação as suas } \\
\text { vontades, interesses } \\
\text { e sentimentos; } \\
\text { - Prever as conse- } \\
\text { qüências de suas } \\
\text { respostas; e } \\
\text { - Autocontrolar-se }\end{array}$ & $\begin{array}{l}\text { 11. Verificação das } \\
\text { atividades do cartaz- } \\
\text { agenda sujeito }\end{array}$ & $\begin{array}{l}\text { 11. Na primeira sessão, o sujeito não } \\
\text { trouxe o cartaz-agenda. Na segunda } \\
\text { sessão, o sujeito trouxe o cartaz-agenda } \\
\text { e tendo realizado mais da metade das } \\
\text { atividades que constavam no cartaz- } \\
\text { agenda, ganhou o "presente". Na Tercei- } \\
\text { ra sessão, o sujeito trouxe o cartaz- } \\
\text { agenda, mas não marcou nenhuma } \\
\text { atividade e não ganhou o presente }\end{array}$ & $\begin{array}{l}\text { 11. Solicitação para uma nova } \\
\text { tentativa e entrega de um que- } \\
\text { bra-cabeças como reforço posi- } \\
\text { tivo quando o sujeito atingiu o } \\
\text { objetivo }\end{array}$ \\
\hline
\end{tabular}

Em relação aos comportamentos mais simples do mapa de ensino ('Olhar para o outro', 'Tocar', 'Ouvir' e 'Esperar'), apresentados à direita do mapa, e em relação aos comportamentos 'Identificar modos de expressão verbal', 'Identificar modos de expressão não-verbal em si e no outro', o desempenho do sujeito foi satisfatório, apresentando a resposta desejada nas atividades planejadas para o ensino desses comportamentos. Em relação aos demais comportamentos que foram objeto de ensino ('Perceber-se em relação a suas vontades, interesses e sentimentos', 'Prever a conseqüência de suas respostas' e 'Autocontrolar-se'), o sujeito apresentou dificuldades em emitir as respostas desejadas. Nesses comportamentos, algumas propriedades da resposta como a frequiência e a topografia não foram emitidas conforme esperadas.

Na atividade de elaboração e verificação do cartazagenda, o sujeito apresentou maior dificuldade em emitir as respostas esperadas, sendo necessária uma modificação no tipo de conseqüência planejada para o ensino dos comportamentos 'Perceber-se em relação a suas vontades, interesses e sentimentos', 'Prever a conseqüência de suas respostas' e 'Autocontrolar-se'. Dessa forma, os atendentes substituíram o reforço social por uma explicação detalhada ao sujeito dos benefícios que a realização das atividades listadas traria a ele e, posteriormente, a proposta de um presente (jogo de quebra-cabeças) como decorrência da realização dessas atividades.

\section{DISCUSSÃO}

O acompanhamento dos desempenhos da criança durante o desenvolvimento do programa para aprendizagem da classe geral denominada comportamento empático possibilitou avaliar, com graus variados de precisão, as diferentes etapas que caracterizaram o trabalho de programar ensino dessa classe de comportamento. Respeitadas as peculiaridades do contexto no qual o programa foi realizado, é possível concluir, de maneira geral, que as contingências oferecidas à criança no e pelo programa foram suficientes para que ela fosse capaz de aprender um conjunto de comportamentos intermediários envolvidos nessa classe geral 
de comportamento. No entanto, a avaliação mais acurada da natureza desses sete comportamentos intermediários aprendidos pela criança possibilita identificar uma lacuna considerável ao comparar com os comportamentos mais complexos que caracterizam a classe geral de comportamento empático.

Do ponto de vista da avaliação do programa no que se refere ao seu desenvolvimento para o ensino dos sete comportamentos, é possível concluir que foi observado o que Sidman (1985) alerta: um programa de ensino necessita ser dividido em pequenas unidades, constituídas por comportamentos mais simples, prérequisitos para o aprendiz aprender o comportamento mais geral e mais complexo, com possibilidades mínimas de errar. Os princípios expressos nos "pequenos passos" (1961) e observados na construção do programa para ensino do comportamento empático, garantiram a eficiência do programa, diminuindo a possibilidade de erro por parte do aprendiz e de propriedades aversivas do programa que eventualmente poderiam decorrer disso. As dificuldades observadas no ensino dos comportamentos de 'Perceber-se em relação a suas vontades, interesses e sentimentos', 'Prever as consequiências de suas respostas' e 'Autocontrolarse', por exemplo, podem ser atribuídas à inexistência de atividades programadas para o ensino de comportamentos mais simples e necessários para a ocorrência desses comportamentos-objetivos considerados mais complexos.

Um exame mais acurado das características do programa desenvolvido possibilita identificar aspectos satisfatórios, como também aspectos que necessitariam ser revistos e aperfeiçoados nesse programa. O primeiro desses aspectos diz respeito à pertinência dos comportamentos que constituíram objetivos intermediários do programa. Uma decomposição de qualquer classe geral de comportamento, tal como o empático, necessita explicitar os comportamentos-intermediários coerentes e significativos para constituir efetivamente em comportamentos pré-requisito em relação ao comportamento mais geral (Botomé, 1996). 'Esperar' foi um dos comportamentos-objetivo intermediário, no programa para aprendizagem do comportamento empático. Ao desenvolver as atividades lúdicas como o jogo da memória e o telefone sem fio, planejadas para o ensino desse comportamento, foi percebido que ele não era um comportamento pertinente e significativo como pré-requisito para aprendizagem da classe mais geral denominada comportamento empático. O comportamento que parece ser mais apropriado, nesse caso, seria o 'Prestar atenção no outro', mais do que 'Esperar'. A apresentação do comportamento 'Esperar' ocorreu como parte da atividade (como regra da brincadeira) e não como uma condição que garantiria a aprendizagem de 'Prestar atenção no outro'.

Um segundo aspecto examinado diz respeito à elaboração das situações de ensino dos comportamentosobjetivos. Para que essas sejam eficientes é necessário considerar a história de reforçamento da pessoa, sujeito do programa, a fim de que as atividades planejadas envolvam os estímulos mais reforçadores. Segundo Matos (2001), é necessário que o planejamento das situações antecedentes para o ensino dos comportamentos-objetivo leve em conta algumas características do aprendiz, tais como o que ele gosta de realizar, o modo como ele o realiza, o que ele já sabe sobre um determinado assunto, entre outras. A atividade do "cartaz-agenda" elaborada para o ensino dos comportamentos 'Perceber-se em relação a suas vontades, interesses e sentimentos', 'Prever as consequiências de suas respostas' e 'Autocontrolar-se', não teve como base de sua elaboração o que era reforçador para a criança, já que a atividade era muito semelhante às suas tarefas escolares que, por sua vez, eram aversivas para o sujeito naquela situação. Nessas atividades, o sujeito apresentou maior dificuldade em desempenhar as tarefas solicitadas.

Foi verificado, ainda na atividade de elaboração do "cartaz-agenda", que a criança não estava motivada para realizar o que lhe fora solicitado e, consequientemente, não apresentou os comportamentos-objetivo desejados. Constatou-se, portanto, que nessa ocasião houve uma escolha equivocada da atividade por parte dos programadores devido, muito provavelmente, a análise na qual não foram consideradas algumas variáveis importantes que se relacionavam com a situação da criança na escola e sua disposição para engajar-se em atividades que tivessem qualquer semelhança com aquelas realizadas em sala de aula. $\mathrm{O}$ fato ocorrido demonstrou que havia algo de errado com o próprio programa e não com o aprendiz, como discute Sidman (1985) em seu artigo sobre "aprendizagem sem erro".

Um terceiro aspecto importante a ser examinado diz respeito à escolha apropriada de uma conseqüência. Essa escolha depende das características do sujeito e da capacidade de sensibilizá-lo. Para o ensino de alguns comportamentos que compuseram o programa, permanecer em silêncio foi escolhido como consequiência aos comportamentos de inquietação motora apresentada pelo sujeito. Nas ocasiões em que comportamentos com essas características eram incompatíveis com aqueles estabelecidos como objetivo da sessão, a conseqüência dada pelos atendentes de permanecer em silêncio serviu como estímulo discriminativo e como condição para que o sujeito emitisse outra resposta, mais próxima aos objetivos programados. 
Um outro aspecto relacionado ainda a escolha apropriada de uma consequiência para aprendizagem de alguns comportamentos, se refere a quando e como realizar a substituição do reforçador artificial, em uma situação de ensino, pela consequiência natural e tornála um reforçador tão eficaz quanto o artificial utilizado, pois segundo Matos (2001) consequiências naturais são mais efetivas para a aprendizagem dos comportamentos, mas em uma programação de ensino devem ser introduzidas de maneira gradual. A atividade do cartaz-agenda, por exemplo, foi programada para que o sujeito se comportasse em função das conseqüências naturais. Não foram planejadas, a princípio, conseqüências artificiais para a apresentação dos comportamentos esperados. Contudo, as consequiências naturais foram insuficientes para a apresentação e manutenção dos comportamentos desejados pelo sujeito, fazendo com que os atendentes tivessem que programar uma conseqüência artificial (um quebra-cabeça) para o engajamento do sujeito na atividade.

Considerou-se também a necessidade de apresentação do reforçador imediatamente após a emissão da resposta pelo sujeito, em conformidade com o princípio da verificação imediata (Teaching Machines Incorporated, 1961). No ensino dos comportamentos 'Perceber-se em relação a suas vontades, interesses e sentimentos', 'Prever as consequiências de suas respostas' e 'Autocontrolar-se', não foi planejada a ocorrência imediata de reforçador após a apresentação desses comportamentos, pois esses foram planejados para serem apresentados fora do contexto terapêutico. Para que esse reforçador imediato ocorresse os pais deveriam ter sido orientados para a efetivação do ensino dos comportamentos desejados. Como a verificação das atividades realizadas pelo sujeito aconteceu apenas quando os pais estavam presentes, ou seja, somente no período noturno, a criança ficou exposta a condição que facilitava mentir sobre assinalar no cartaz-agenda o comportamento listado, não ocorrendo assim a aprendizagem dos comportamentos-objetivos.

A necessidade de avaliação da possibilidade de ajuda de familiares para efetivação das aprendizagens de alguns comportamentos, com qualquer nível de complexidade, foi outro aspecto analisado. Essa avaliação necessita ser feita principalmente quando as atividades precisam ser feitas fora do contexto clínico e conduzidas pelos pais ou demais pessoas envolvidas com a criança. Na condução de algumas atividades a orientação oral aos pais, por exemplo, pode ser insuficiente, necessitando de treinos mais sistemáticos e prolongados. Na atividade de verificação do cartazagenda, por exemplo, o pedido de cooperação da mãe como um recurso para a verificação das tarefas do cartaz-agenda realizadas pelo sujeito não foi suficiente para a instalação do repertório programado.

No caso da criança atendida, os pais mostraram estar ausentes do cotidiano da criança, o que prejudicou o acompanhamento do progresso feito por ela na apresentação de comportamentos mais apropriados ao contexto e à natureza das solicitações feitas por eles e pela escola. Entretanto, nas tentativas de inserir os pais na aplicação do programa de ensino do comportamento empático, ora como reforçadores de respostas almejadas, ora como estímulos discriminativos de respostas consideradas indesejáveis, foram obtidos alguns resultados satisfatórios. Por meio de entrevistas com os pais e de observação direta na casa do sujeito, foram identificadas demonstrações de carinho e afeto, maior interação entre a criança e seus pais e maior compreensão das necessidades da criança pelos pais. A importância da interação com os pais para a aprendizagem de comportamentos sociais pela criança é demonstrada por estudos como os de Baumrind (1966), Caballo (2003) e Löhr (2003). Del Prette e Del Prette (2005), por sua vez, ressaltam a necessidade dos pais serem esclarecidos acerca da aplicação de programas de treinamento em habilidades sociais para que estes funcionem como co-terapeutas.

Outro aspecto a ser considerado é aquele referente a necessidade de caracterizar com precisão o repertório de entrada do sujeito do programa. O tempo de aprendizagem dos comportamentos constituintes do programa de ensino pode variar conforme a história de aprendizagem do sujeito. Alguns comportamentosobjetivos foram aprendidos pelo sujeito mais rapidamente que outros. $\mathrm{O}$ sujeito apresentou os comportamentos de 'Olhar' e 'Esperar' logo após a solicitação realizada pelos atendentes, o que sugere que ele, ou já apresentava esses comportamentos como parte de seu repertório, ou havia aprendido comportamentos que se tornaram facilitadores para as aprendizagens desses atuais. A criança, sujeito do programa de ensino do comportamento empático, apresentou o comportamento de 'Tocar' logo após a solicitação dos atendentes, embora esse comportamento precisasse ser modelado para que fosse apresentado com a topografia apropriada.

O ensino de alguns comportamentos por meio de regras não foi eficaz. As dificuldades demonstradas pelo sujeito para a realização das atividades propostas no cartaz-agenda, por exemplo, podem ser explicadas pela falta de um repertório comportamental na criança que a impossibilitou de ficar sob controle das instruções verbais destinadas para realização de tal atividade. Foi possível conjeturar que, como a criança permanecia muito tempo sozinha em casa e não era orientada 
por regras, a atividade escolhida que consistia no cumprimento de algumas instruções solicitadas não foi eficiente para o ensino dos comportamentosobjetivos envolvidos a serem garantidos por essa atividade. Para Matos (2001a), os comportamentos controlados por meio de regras são modelados por meio de consequiências artificiais, como a aprovação social. Assim, para que as regras suscitem um comportamento é necessário que o comportamento de seguir regras tenha sido reforçado no passado, por meio de aprovação social. As regras, portanto, exercem controle discriminativo devido a uma história de reforçamento social para o comportamento de responder de acordo com as regras estabelecidas para determinada situação. Tal fato exemplifica a necessidade de aferir com mais precisão qual o repertório de entrada do aprendiz, sujeito de um programa de ensino.

Por último, é necessário considerar a importância da aferição do grau de generalização dos comportamentos aprendidos em contexto clínico para outros ambientes. No caso considerado, é possível concluir que, de maneira geral, foi satisfatório para uma parte dos comportamentos-objetivo, em especial para os comportamentos mais simples. As atividades foram planejadas para o ensino dos comportamentos-objetivo de forma que a criança obtivesse uma aprendizagem eficaz, apresentando o maior grau possível de generalização desses comportamentos. Foi percebida a generalização dos comportamentos de 'Olhar', 'Esperar', 'Ouvir' e 'Tocar' para outros contextos que não o clínico, tal como o ambiente escolar e familiar. A generalização desses comportamentos foi percebida por meio de entrevistas realizadas com a professora e com os pais da criança, com observações realizadas na escola e na casa do sujeito e com os comportamentos apresentados pela criança em relação aos seus pais quando o sujeito saía da sessão terapêutica. Relatos da professora e da mãe da criança exemplificam a generalização dos comportamentos aprendidos pela criança em contexto clínico para outros ambientes: "[o sujeito] encontra-se mais aberto, relacionando-se melhor com seus colegas e conversando com eles" (professora); "[o sujeito] não lambe mais a mesa ao fazer os deveres, não se morde mais como antes, chupando raramente os ombros da camisa..." (mãe).

Por um processo de generalização, a aprendizagem de alguns comportamentos constitutivos do programa de ensino possibilitou que o sujeito modificasse outros comportamentos relatados como queixa no início do processo terapêutico. Com observações domiciliares e na escola, foi percebido que o sujeito passou a apresentar comportamentos que não eram apresentados antes dos atendimentos, tais como 'sentar em sala de aula prestando atenção na professora', o que fez com que suas notas em avaliações aumentassem, "prestar atenção nos pais' quando estes lhes dirigiam a palavra, 'brincar com o irmão' sem machucá-lo, 'extinguir comportamentos autolesivos', dentre outros comportamentos observados.

O grau de generalização dos comportamentos 'Identificar modos de expressão verbal' e 'Identificar modos de expressão não-verbal em si e no outro' não pode ser aferido por meio das informações obtidas por meio de entrevistas com os pais e com a professora do sujeito, nem por meio das observações direta na escola e em sua casa. Já no que se refere aos comportamentos de 'Perceber-se em relação a suas vontades, interesses e sentimentos', 'Prever as consequiências de suas respostas' e 'Autocontrolar-se', há dúvidas de que estes não foram realmente aprendidos pela criança por meio das atividades planejadas para as sessões terapêuticas. A dificuldade observada no ensino desses comportamentos sugere que a programação de apenas uma atividade fora insuficiente para a aprendizagem desses comportamentos-objetivo considerados mais complexos, fato este que dificultou a aferição do grau de generalização dessas aprendizagens para outros contextos.

Do ponto de vista de uma avaliação da natureza dos comportamentos intermediários aprendidos pela criança (tocar, escutar, esperar, olhar para o outro, identificar modos de expressão verbal e não verbal, perceber-se em relação a suas vontades, interesses e sentimentos) a despeito de serem necessários para um desempenho socialmente competente (Del Prette \& Del Prette, 1999, 2005), é perceptível que eles não são ainda suficientes para capacitar o sujeito a lidar de modo caracteristicamente empático nas suas relações familiares e sociais de maneira geral. Ainda que as aprendizagens desses comportamentos básicos constituam um avançar para os primeiros "degraus" do comportamento empático, e que tenham resultado em modificações importantes de alguns comportamentos que constituíram em queixa inicial (brigas com irmão, birra, xingamentos etc.), há necessidade de contemplar uma gama maior dos comportamentos considerados pré-requisitos, principalmente aqueles cuja dimensão afetiva é mais saliente. Por exemplo, não foi ensinado ao sujeito "identificar emoções próprias e dos outros", nem "expressar emoções" seja de maneira verbal ou não-verbal.

A conclusão de que as aprendizagens dos sete comportamentos-objetivo foram eficazes pela generalização feita pelo sujeito para os contextos escolar e familiar, fica relativizada pela consideração do que autores como Falcone (1999) ou Del Prette e Del Prette 
(2005) analisam acerca do que define ser empático. Para aprender a compreender os sentimentos e a perspectiva do outro, e comunicar esse entendimento de maneira que o outro se sinta compreendido, seria necessário que o programa fosse cumprido na íntegra. Sem dúvida, a criança aprendeu alguns pré-requisitos, o que pode ser considerado um grau no sentido de comportar-se empaticamente, mas é pouco se comparado, por exemplo, aos resultados obtidos por Falcone (1999) com seu programa de treinamento da empatia, guardadas as devidas proporções entre o programa de treinamento de empatia conduzida pela autora e o aqui relatado. A contribuição que pode ser destacada em relação ao presente programa é mais voltada para a elaboração de um programa de ensino e a demonstração que, principalmente para crianças, muitas vezes se faz necessário a aprendizagem de comportamentos muito básicos e possibilita avançar com mais segurança na direção dos comportamentos mais complexos almejados.

Em síntese, a avaliação feita de um programa para ensinar uma criança comportamentos envolvidos na classe geral denominada comportamento empático possibilitou identificar alguns benefícios para a criança do ponto de vista de acrescentar ao seu repertório comportamentos que facilitaram relacionar-se de maneira melhor principalmente com seu ambiente familiar e escolar, ainda que não a tivesse capacitado para comportar-se empaticamente de maneira efetiva. Possibilitou ainda destacar características apresentadas por um programa cuja eficácia dependeu de um conjunto de aspectos críticos a serem observados, corroborando o que autores como Botomé (1997), Caballo (1996), Falcone (1999 e 2002), Matos (2001), Sidman (1985), entre outros destacam como importantes ao programar ensino, na aprendizagem do comportamento empático, e no aprimoramento de habilidades sociais, de maneira geral. Ainda que fique evidente a necessidade de aprofundamentos na avaliação feita, com o desenvolvimento dos comportamentos mais complexos envolvidos na classe geral do comportamento empático, e de correções de muitos aspectos do programa, é possível considerar como uma contribuição para o avanço de estudos para a proposição, implementação de procedimentos que sejam cada vez mais eficazes e eficientes para o ensino de comportamentos significativos para quem deles necessitar.

\section{REFERÊNCIAS}

Baumrind, D. (1966). Effects of authoritative control on child behavior. Child Development, 37, 887-907.
Botomé, S. P. (1980). Objetivos comportamentais no ensino: a contribuição da Análise Experimental do Comportamento. Tese de doutorado apresentada ao Programa de Pós-graduação em Psicologia Experimental, Universidade de São Paulo, São Paulo, SP.

Botomé, S. P. (1996). Um procedimento para encontrar os comportamentos que constituem as aprendizagens envolvidas em um objetivo de ensino. Trabalho não publicado, Universidade Federal de São Carlos, São Carlos, SP.

Botomé, S. P. (1997). Educação, conhecimento, comportamento humano e necessidades sociais. Trabalho não publicado, Universidade Federal de São Carlos, São Carlos, SP.

Brittes, T. P. (2003). Um instrumento para identificação de expressões faciais. Trabalho não publicado, Universidade Federal de Santa Catarina, Florianópolis, SC.

Burleson, B. R. (1985). The production of comforting messages: social cognitive foundations. Journal of Language and Social Psychology.

Caballo, V. E. (1996). O treinamento em habilidades sociais. Em V. Caballo (Org.), Manual de técnicas de terapia e modificação de comportamento (pp. 361-398). São Paulo: Santos Editora.

Caballo, V. E. (2003). Manual de avaliação e treinamento das Habilidades Sociais. São Paulo: Santos Editora.

Cecconello, A. M., Antoni, C. \& Koller, S. H. (2003). Práticas educativas, estilos parentais e abuso físico no contexto escolar. Psicologia e Estudo, 8 (número especial), 45-54.

Davis, M. H. \& Outhout, H. A. (1987). Maintenance of satisfaction in romantic relationships: Empathy and relational competence. Journal of Personality and Social Psychology, 53, 397410.

Del Prette, Z. A. P. \& Del Prette, A. (1999). Psicologia das habilidades sociais: Terapia e educação. Petrópolis: Vozes.

Del Prette, Z. A. P. \& Del Prette, A. (2002). Transtornos psicológicos e habilidades sociais. Em H. J. Guilhardi (Org.), Sobre comportamento e cognição: Contribuições para a construção da teoria do comportamento. Vol. 10. (pp. 377-386). Santo André: ESETec Editores Associados.

Del Prette, Z. A. P. \& Del Prette, A. (2005). Psicologia das habilidades sociais na infância: Teoria e prática. Petrópolis: Vozes.

Eagle, K. A. (2004). The effects of parental empathic responses on children's aggressive behavior. Dissertação publicada em The Sciences and Engineering, 64 (7-B).

Falcone, E. (1999). A avaliação de um programa de treinamento da empatia com universitários. Revista Brasileira de Terapia Comportamental e Cognitiva, 1(1), 23-32.

Falcone, E. (2002). Contribuições para o treinamento em habilidades em interação. Em H. J. Guilhardi (Org.), Sobre comportamento e cognição: contribuições para a construção da teoria do comportamento. Vol. 10 (pp. 91-104). Santo André: ESETec Editores Associados.

Falcone, E. (2002a). A evolução das habilidades sociais e o comportamento empático. Em E. F. M. Silvares (Org.), Estudos de caso em psicologia clínica comportamental infantil. Vol. 2. (pp. 49-77). São Paulo: Papirus.

Feshbach, N. D. (1983). Learning to care: A positive approach to child training and discipline. Journal of Clinical Child Psychology, 12(3), 266-271. 
Feshbach, N. D. \& Feshbach, S. (1982). Empathy training and the regulation of aggression: Potentialities and limitations. Academic Psychology Bulletin, 4(3), 399-413.

Fine, V. K. \& Therrien, M. E. (1977). Empathy in the doctorpatient relationship: Skill training for medical students. Journal of Medical Education, 52 (9), 752-757.

Garcia-Serpa, F. A., Meyer, S. B. \& Del Prette, Z. A. P. (2003). Origem social do relato de sentimentos: Evidência empírica indireta. Revista Brasileira de Terapia Comportamental e Cognitiva, 5(1), 21-29.

Haugen, R. E. (1999). The effects of perspective-taking on empathy development in adult male sex offenders. Dissertação publicada em The Sciences and Engineering, 60 (1-B).

Henderson, K. (1998). Moral reasoning, empathy, and behavior of students with and without emotional and behavioral disorders and learning disabilities: Impact of a structured program of experiential learning activities involving animals and nature. Dissertação publicada em Humanities and Social Ssciences, 58 (11-A).

Kirk, W. G. \& Thomas, A. H. (1982). A brief inservice training strategy to increase levels of empathy of psychiatric nursing personnel. Journal of Psychiatric Treatment and Evaluation, $4(2), 177-179$

Linnell, K. E., Stechmann, A. M. \& Watson, C. G. (1975). Resocialization of schizophrenic patients. American Journal of Occupational Therapy, 29(5), 288-290.

Lörh, S. S. (2003). Estilos parentais e desenvolvimento de habilidades sociais. Em M. Z. Brandão (Org.), Sobre comportamento e cognição: a história e os avanços, a seleção por conseqüências em ação. Vol. 11 (pp. 476-481). Santo André: ESETec Editores Associados.

Lubi, A. P. L. (2003). Estilo parental e comportamento socialmente habilidoso da criança com pares. Em M. Z. Brandão (Org.), Sobre comportamento e cognição: a história e os avanços, a seleção por conseqüências em ação. Vol. 11 (pp. 536541). Santo André: ESETec Editores Associados.

Matos, M. A. (2001). Análise de contingências no aprender e no ensinar. Em E. S. de Alencar (Org.), Novas contribuições da
Psicologia aos processos de ensino e aprendizagem (pp. 141165). São Paulo: Cortez Editora.

Matos, M. A. (2001a). Comportamento governado por regras. Revista Brasileira de Terapia Comportamental e Cognitiva, 3(2), 51-66.

Nale, N. (1998). Programação de ensino no Brasil: O papel de Carolina Bori. Psicologia USP, 9(1), 275-301.

Organização Mundial da Saúde (1993). Classificação Estatística Internacional de Doenças e Problemas Relacionados à Saúde $10^{\mathrm{a}}$ Revisão (CID-10). Descrições clínicas e diagnósticas. Porto Alegre: Artes Médicas.

Reeve, S. A. (2001). Effects of modeling, video modeling, prompting, and reinforcement strategies on increasing helping behavior in children with autism. Dissertação publicada em The Sciences and Engineering, 62 (3-B).

Rogge, R. D., Cobb, R. M., Johnson, M., Lawrence, E. \& Bradbury, T. N. (2002). The CARE program: a preventive approach to marital intervention. Em N. S. Jacobson \& A. S. Gurman (Orgs.), Clinical handbook of couple therap (3a.ed.) (pp. 420435). New York: Guilford Press.

Sidman, M. (1985) Aprendizagem-sem-erros e sua importância para o ensino do deficiente mental. Psicologia, 11(3), 1-15.

Teaching Machines Incorporated - A Division of Crolier, Incorporated (1961). Ensino programado. Não publicado.

Weber, L. N. D., Prado, P. M., Viezzer, A. P. \& Brandenburg, O. J. (2004). Identificação de estilos parentais: O ponto de vista dos pais e dos filhos. Psicologia: Reflexão e Crítica, 17(3), 323-331.

Webster-Stratton, C. \& Reid, M. J. (2003). Treating conducts problems and streningthening social and emotional competence in young children: The dina dinosaur treatment program. Journal of emotional and behavioral disorders, 11 (3), 130-143.

Recebido: 10/10/2005 Revisado: 1212/2005 Aceito: 30/12/2005

\section{Sobre os autores:}

Aline Vettorazzi: Aluna do Curso de Graduação em Psicologia da Universidade Federal de Santa Catarina (vttzz@terra.com.br) Eluana Frare: Aluna do Curso de Graduação em Psicologia pela Universidade Federal de Santa Catarina (eluanaf@ hotmail.com) Fernanda Chedid de Souza: Aluna do Curso de Graduação em Psicologia pela Universidade Federal de Santa Catarina (nandachedid@hotmail.com)

Fernanda Pamplona de Queiroz: Aluna do Curso de Graduação em Psicologia pela Universidade Federal de Santa Catarina (fernandafpq@yahoo.com.br)

Gabriel Gomes de Luca: Aluno do Curso de Graduação em Psicologia pela Universidade Federal de Santa Catarina - Bolsista do CNPq - PIBIC (gabrielgomesdeluca@yahoo.com.br)

Luciana Moskorz: Aluna do Curso de Graduação em Psicologia pela Universidade Federal de Santa Catarina (lumoskorz@yahoo.com.br)

Olga Mitsue Kubo: Doutora em Ciências pela Universidade de São Paulo e Professora do Departamento de Psicologia da Universidade Federal de Santa Catarina (ok@cfh.ufsc.br) 